\title{
RE-ENVISIONING OF POSTHUMAN AND TRANSHUMAN: CYBORG, ROBOT, AND A.I IN WILLIAM GIBSON'S NEUROMANCER
}

\begin{abstract}
:
William Gibson's Neuromancer introduces diverse types of transhumans and posthumans like cyborg, robot, A.I. These show how the future community will develop with symptoms of potential social and cultural problems the we are going to face. There are no normal humans in the novel that we can see in these days. This paper will highlight how the different transhumans and posthumans interact in social and cultural hi-tech society and what the author thinks the machinic and artificial world will need to be a desirable one.

Except for a few characters like Tessier and Marie-France, most of them could be called cyborg, robot, and A.I. Even Case, a cyberspace cowboy, who had a human body is forced to carries some vital chips in his body after he made a fatal mistake. Julius Deane is "one hundred and thirty-five years old, his metabolism assiduously warped by a weekly fortune in serums and hormones" and "the code of his DNA" reset by genetic surgeons in Chiba. As a warrior, Molly is a kind of cyborg, whose glasses are "surgically inset, sealing her sockets" while Riviera is "a product of the rubble rings that fringe the radioactive core of old Bonn." Armitage's memories are artificially operated and implanted into Willis Corto's body while bodiless Flatline is a computer human downloaded with McCoy Pauley's brain. Hideo is "almost certainly the ninja clone" whose "brown chest was bare and smooth." As the children of Tessier and Marie-France, 3Jane and 8jean are probably cloned ones who can inherit forever their parents' immortal global corporation. Wintermute, a cold and goal oriented Artificial Intelligence, is "hive mind, decision maker, effecting change in the world outside" while Neuromancer is "personality" and "immortality."

William Gibson's Neuromancer reminds us of George Orwell's work, 1984, depicting the future world that he imagined in the 1940s. William Gibson suggests diverse types of humans who will play a pivotal role in the future world. It is needless to say that cyborgs and robots along with A.I. - the posthumans and transhumans not different from us today - are expected to actively engage in normal social and cultural life. Nevertheless, it seems that the author would like to emphasize the combination of the warm personality and cold rationality even in the machinic and artificial world which Marie-France would materialize by "the compulsion that had driven the thing(Wintermute) to free itself, to unite with Neuromancer."
\end{abstract}

\section{Keywords:}

Artificial Intelligence, Cyborg, Robot, Neuromancer, Wintermute, Posthumans and Transhumans 